\title{
Orthotic (helmet) therapy in the treatment of plagiocephaly
}

\author{
Jo Ling Goh, B.A., ${ }^{1}$ David F. Bauer, M.D., ${ }^{2}$ Susan R. Durham, M.D., ${ }^{2}$ \\ and Mitchell A. Stotland, M.D. ${ }^{3}$ \\ ${ }^{1}$ Geisel School of Medicine, Hanover; and Departments of ${ }^{2}$ Neurosurgery and ${ }^{3}$ Plastic Surgery, \\ Dartmouth-Hitchcock Medical Center, Lebanon, New Hampshire
}

\begin{abstract}
Object. The goal of this study was to review the current literature on orthotic (helmet) therapy use in the treatment of deformational plagiocephaly.

Methods. PubMed was used to search English articles using the medical subject headings "deformational plagiocephaly" and "orthosis," and "deformational plagiocephaly" and "helmet."

Results. Forty-two articles were found. There were no Class I studies, 7 Class II studies, 1 Class III study, and 13 Class IV studies. Cranial orthoses have been shown to be effective in treating deformational plagiocephaly. It continues to be debated as to whether the statistical significance of treatment with cranial orthoses compared with conservative therapies is clinically significant. Children older than 12 months of age with deformational plagiocephaly may still benefit from orthotic therapy. The long-term effects of orthotic therapy are controversial.

Conclusions. There is a lack of Class I literature evidence supporting the use of helmet therapy in deformational plagiocephaly. There are controversies surrounding the use of orthotic therapy such as appropriate use, cost, use in older children, and long-term outcomes. Clinical indications for orthotic therapy need to be better defined with further research studies.
\end{abstract}

(http://thejns.org/doi/abs/10.3171/2013.7.FOCUS13260)

KEY WoRdS - deformational plagiocephaly - cranial orthoses • helmet therapy

$\mathrm{I}$ N 1992, the American Academy of Pediatrics Task Force recommended that infants be placed on their backs during sleep to reduce the risk of sudden infant death syndrome. Following this "Back to Sleep" recommendation, a significant drop in sudden infant death syndrome and an associated increase in the incidence of deformational plagiocephaly was noted,,$^{1,21,28}$ and the use of cranial orthoses have been commonplace for the treatment of deformational plagiocephaly.

\section{Brief History of Orthotic Therapy}

A cranial orthotic device is also referred to as a cranial helmet, cranial orthosis, or cranial band. These devices were first described in the scientific literature by Clarren et al. in 1979. ${ }^{4}$ However, the idea of using artificial cranial deformation was conceived at least 30,000 years ago in ancient Peru, ${ }^{2}$ where infant skulls were artificially shaped using external compression with fixed boards and pads ${ }^{2}$ or ritual head wrapping. ${ }^{25}$

Modern-day cranial orthotic devices use that same principle. They are usually custom fit and molded to allow for growth in certain regions of the cranium and concomitant growth restriction in others. Most helmets apply passive restriction rather than active compression forces, $5,9,12,13$ encouraging the infant's malleable and rapidly expanding skull to grow into a desired configuration. There are helmets that reportedly apply active molding forces to aid in the corrections, such as the Dynamic Orthotic Cranioplasty Band (Cranial Technologics, Inc.) and the pneumatic orthotic helmet described by Lee et al. ${ }^{16}$ Some researchers argue that there is no true distinction between passive and active devices because the application of constant active pressure would easily exceed the ischemic tolerance of the overlying skin and lead to pressure ulceration. ${ }^{36}$

In the US, many cranial orthotic devices have been FDA regulated. There are currently 37 FDA-approved cranial orthoses listed on the FDA website (http://www. accessdata.fda.gov/scripts/cdrh/cfdocs/cfPMN/pmn.cfm; Table 1). Of note, there has been some controversy surrounding the regulation of cranial orthoses. Many argue that FDA regulation helped standardize the industry, ${ }^{19}$ while others argue that it has caused an increase in treatment-associated costs due to centralized production of the orthoses by larger companies. ${ }^{32}$

\section{Methods of Anthropometric Assessment}

Cranial measurements have traditionally been ob- 
TABLE 1: List of FDA-approved cranial orthotic devices*

\begin{tabular}{|c|c|c|c|}
\hline Product Name & Company & Approval Date & FDA $510(K)$ No \\
\hline Dynamic Orthotic Cranioplasty Band; Doc Band & Cranial Technologies, Inc. & $5 / 29 / 1998$ & K964992 \\
\hline Opi Band & Orthomerica Products, Inc. & $7 / 7 / 2000$ & K001167 \\
\hline Craniocap & Gillette Children's Specialty Healthcare & $10 / 30 / 2000$ & K000861 \\
\hline Hanger Cranial Band & Hanger Orthopedic Group, Inc. & $12 / 8 / 2000$ & K001669 \\
\hline Cranial Molding Orthosis & Orthotic Solutions, Inc. & $4 / 25 / 2001$ & K010273 \\
\hline Danmar Products Michigan Cranial Helmet & Danmar Products, Inc. & $5 / 29 / 2001$ & K003630 \\
\hline Clarren Helmet & Children's Hospital \& Medical Center & $6 / 6 / 2001$ & K003035 \\
\hline Ballert Cranial Molding Helmet & Gema, Inc. & $6 / 12 / 2001$ & K011433 \\
\hline RHS Helmet & Restorative Health Svs, Inc. & $9 / 19 / 2001$ & K012007 \\
\hline Cranial Helmet & Children's Hospital & $10 / 29 / 2001$ & K013458 \\
\hline Lerman \& Son Cranial Orthosis Helmet & Lerman \& Son & $11 / 20 / 2001$ & K012830 \\
\hline Molded Cranial Helmet & Fairview Orthopedic Laboratory & $11 / 28 / 2001$ & K012920 \\
\hline Plagiocephalic Applied Pressure Orthosis; P.A.P. Orthosis & Scott E Allen CP & $1 / 17 / 2002$ & K012804 \\
\hline Orthosis Helmet Molding & Precision Prosthetics \& Orthotics, Inc. & $2 / 5 / 2002$ & K013700 \\
\hline Becker Band Cranial Remolding Orthosis & Becker Orthopedic Appliance Co. & $2 / 5 / 2002$ & K013719 \\
\hline Static Cranioplasty Orthosis & Eastern Cranial Affiliates & $4 / 12 / 2002$ & K020448 \\
\hline O\&P Cranial Molding Helmet & Orthotic \& Prosthetic Lab, Inc. & $7 / 1 / 2002$ & K021221 \\
\hline Cranial Symmetry System & Beverly Hills Prosthetics Orthotics, Inc. & $9 / 9 / 2002$ & K022273 \\
\hline $\begin{array}{l}\text { Loma Linda University Medical Center (LIUMC) Cranial } \\
\text { Remolding Helmet }\end{array}$ & $\begin{array}{l}\text { Rehabilitation Institute Loma Linda University } \\
\text { Med }\end{array}$ & $1 / 13 / 2003$ & K023572 \\
\hline Providence Molding Helmet & Northeast Orthotics and Prothetics, Inc. & $7 / 18 / 2003$ & K030669 \\
\hline Danmar Products Cranial Adjustive Prosthesis & Danmar Products, Inc. & $10 / 31 / 2003$ & K013452 \\
\hline COPC Band & Center for Orthotic and Prosthetic Care, LLC & $11 / 13 / 2003$ & K021594 \\
\hline Cranial Helmet & Otto Bock Health Care, LP & $9 / 9 / 2004$ & K041215 \\
\hline Doc Band-Postop & Cranial Technologies, Inc. & $12 / 17 / 2004$ & K042385 \\
\hline O\&P Bivalve Cranial Molding Helmet & Orthotic \& Prosthetic Lab, Inc. & $12 / 22 / 2006$ & K063395 \\
\hline Cranial Solution Orthosis & Cranial Solutions & $7 / 2 / 2007$ & K063133 \\
\hline CCRO (Craniocephalic Custom Remolding Orthosis) & Mike Miner & $9 / 10 / 2007$ & K070694 \\
\hline Hanger Cranial Band & Hanger Prosthetics \& Orthotics, Inc. & $1 / 9 / 2008$ & K072566 \\
\hline Boston-Band Cranial Remodling Orthosis & Boston Brace Intl., Inc. & $1 / 22 / 2008$ & K072862 \\
\hline Starlight & Orthomerica Products, Inc. & $9 / 12 / 2008$ & K081994 \\
\hline Starlight & Orthomerica Products, Inc. & $10 / 31 / 2008$ & K082945 \\
\hline Starband & Orthomerica Products, Inc. & $12 / 5 / 2008$ & K082950 \\
\hline Camlab Cranial Orthosis Helmet & Biosculptor Corporation & $1 / 27 / 2009$ & K081787 \\
\hline Michigan Cranial Reshaping Orthosis & Danmar Products, Inc. & $1 / 6 / 2010$ & K090341 \\
\hline AOI Cranial Helmet & Advanced Orthopro, Inc. & $4 / 18 / 2011$ & K103362 \\
\hline Cranial Remolding Orthosis & Orthotic Care Services LLP & 8/15/2011 & K111247 \\
\hline Boston Band & Boston Brace Intl., Inc. & $8 / 22 / 2011$ & K111609 \\
\hline
\end{tabular}

* All information taken directly from FDA website (http://www.accessdata.fda.gov/scripts/cdrh/cfdocs/cfPMN/pmn.cfm).

tained using anthropometric calipers. Recent technological advances such as photogrammetry ${ }^{25,35}$ or $3 \mathrm{D}$ surface scanning with a laser ${ }^{31,41}$ allow clinicians and researchers to use more accurate and efficient measurement. ${ }^{41}$ The common anthropometric measurements used are explained in Table 2.

\section{Current Research on Helmet Therapy}

The rise in prevalence of deformational plagiocephaly secondary to the "Back to Sleep" campaign has fueled a significant amount of research regarding the use of cranial orthotic devices as a means of correcting infantile cranial deformity. This paper focuses on the role of orthotic therapy in treating deformational plagiocephaly.

\section{Methods}

PubMed was used to search English articles with the following medical subject heading terms "deformational plagiocephaly" and "orthosis," and "deformational plagiocephaly" and "helmet." To judge the quality of the studies, the following classifications were used: Class I, 
Orthotic (helmet) therapy in treatment of plagiocephaly

TABLE 2: Methods of anthropometric assessment

\begin{tabular}{|c|c|}
\hline Measurement & Definition \\
\hline cranial width/breadth & greatest transverse diameter (maximum biparietal diameter) of the head, on a horizontal plane \\
\hline cranial length & $\begin{array}{l}\text { measured from the glabella (most prominent midpoint btwn eyebrows) to the opisthocranion (most prominent } \\
\text { point on the occiput) }\end{array}$ \\
\hline cephalic index/cranial index & (cranial width / cranial length) $\times 100$ \\
\hline occipital-frontal transcranial diameter & $\begin{array}{l}\text { transverse cranial diameters measured obliquely from supraorbital rim directly above pupil, orbitale superius, } \\
\text { to the occipital landmark directly posterior to the orbitale superius on the contralateral side }\end{array}$ \\
\hline $\begin{array}{l}\text { transdiagonal difference/transcranial } \\
\text { diagonal difference }\end{array}$ & difference btwn the 2 occipital-frontal transcranial diameters \\
\hline cranial vault asymmetry & $\begin{array}{l}\text { distance btwn It frontozygomatic point \& rt euryon point - distance btwn rt frontozygomatic point \& It euryon } \\
\text { point }\end{array}$ \\
\hline cranial vault asymmetry index & $\begin{array}{l}\text { (cranial vault asymmetry / shorter frontozygomatic-euryon distance) } \times 100 ; 0 \%=\text { perfect symmetry, score } \\
>3.5 \%=\text { significant asymmetry }\end{array}$ \\
\hline cranial base asymmetry & inion point to rt tragus point - inion point to It tragus point \\
\hline orbitotragial depth asymmetry & rt exocanthion point to rt tragus point - It exocanthion point to It tragus point \\
\hline
\end{tabular}

evidence from a randomized controlled trial; Class II, evidence from a prospective trial that compared more than 2 treatments in a nonrandomized manner; Class III, evidence from a prospective or retrospective case series with historical controls; and Class IV, evidence from a prospective or retrospective case series with no control or comparison group.

\section{Results}

Forty-two articles were found using the search terms detailed above. Six articles were excluded because they were not directly related to cranial orthoses therapy in deformational plagiocephaly $(\mathrm{n}=5)$, or involved nonhuman subjects $(\mathrm{n}=1)$. Of the remaining 36 papers, 21 were primary research literature articles, $, 5,6,9-17,20,25,26,31,33,35-37,39,41$ 12 were reviews, $7,8,22-24,29,30,32,34,38,40,422$ were letters, ${ }^{3,18}$ and 1 described the methodology of an ongoing randomized controlled trial. ${ }^{43}$ Of the 21 primary research articles, there were 7 Class II studies, ${ }^{10,11,13,17,25,31,36} 1$ Class III study, ${ }^{33}$ and 13 Class IV studies. ${ }^{5,6,9,12,14-16,20,26,35,37,39,41}$

\section{Discussion}

This review article focuses on the controversies that exist in the use of orthotic therapy in deformational plagiocephaly.

\section{Helmet Therapy in Comparison With Conservative Treatments}

There is a lack of Class I evidence surrounding the use of helmet therapy in deformational plagiocephaly, as has been noted in previous review articles. ${ }^{7,22,32} \mathrm{Nev}-$ ertheless, the general consensus is that cranial orthoses are indeed as efficacious, if not more efficacious, in treating deformational plagiocephaly as compared with other more conservative treatments. ${ }^{22,23,32}$

Studies of helmet therapy often target patients who have already undergone unsuccessful osteopathy and/or physiotherapy as conservative measures. ${ }^{5}$ This experience consequently introduces a selection bias whereby patients who have more severe deformational plagiocephaly are selected to take part in orthotic trials. It is uncertain whether orthotic therapy is warranted to treat infants with mild to moderate deformational plagiocephaly. ${ }^{27}$ Moss prescribed only neck-stretching exercises, positioning changes, and parental training to 66 infants with deformational plagiocephaly of mild to moderate severity, and found that the outcomes were comparable to infants who were treated by headbands in a previous study. ${ }^{27}$ However, because the rate of correction is faster if infants start using the helmets earlier, ${ }^{13,36}$ parents and providers alike may feel the pressure to begin infants with mild to moderate cases of deformational plagiocephaly on helmet therapy to prevent long-term cosmetic issues.

The actual clinical significance of a change of a few millimeters when using orthotic therapy compared with repositioning therapy is also another issue of contention. For example, Graham et al. compared repositioning with orthotic therapy and showed that orthotic therapy resulted in a $61 \%$ decrease in the reduction of diagonal difference compared with $52 \%$ in the repositioning group. ${ }^{10}$ While a difference of $9 \%$ was statistically significant, the absolute change was actually only $0.16 \mathrm{~cm}$ (or $1.6 \mathrm{~mm}$ ). Similarly, Lipira et al. showed in his 2010 prospective cohort study that orthotic helmets yielded statistically superior reduction in overall head asymmetry compared with active repositioning via a novel 3D surface scanning technique. ${ }^{17}$ However, this study also questioned the actual clinical significance of these statistically significant values in terms of quality of life, long-term outcomes, and parental satisfaction. Interestingly, another study that was aimed toward determining the optimal time to begin helmet therapy noted that some parents requested to withdraw prior to study aims being met, as they believed that the asymmetry was already corrected. ${ }^{36}$

Two studies have attempted to address the issue of clinical significance compared with statistical significance by also incorporating measurements of parental satisfaction into their research study. Both studies showed that subjective assessments are often discordant with objective measurements. ${ }^{12,14}$ Katzel et al. measured both 


\section{J. L. Goh et al.}

head asymmetry and improvement in ear position following helmet therapy. ${ }^{12} \mathrm{He}$ also asked parents to subjectively rate the improvements in both head asymmetry and ear position before and after therapy. Interestingly, the parents' perceived improvement in ear position were similar in magnitude to the changes in head shape, despite less impressive changes in actual ear offset.

The issue of ear position was made even more interesting in a study by Kluba et al. ${ }^{14}$ They observed that parents often noted ear shifts because they often have infants in their laps, and ear displacements were particularly apparent when observed from the vantage point of the parent from above. In their study, $40 \%$ of babies with deformational plagiocephaly without initial ear shift showed subsequent increased ear shift after being treated with cranial orthoses. However, they found that subjective impressions of the babies' ear positions as measured by ratings of medical doctors had a low concordance rate when compared with objective measures of ear shift.

The issue of clinical significance correlating with statistical significance is not a trivial one, as this could potentially affect the prevalence of use of cranial orthoses in deformational plagiocephaly. Ultimately, it is a cost-benefit analysis. These cranial orthotic devices cost anywhere from $\$ 1000$ to $\$ 3500 .^{23}$ Part of the high cost is secondary to the fact that the companies that make most devices pride themselves on custom-making the orthosis for the baby. However, Thompson et al. reported positive results in 2009 while using a generic-sized soft foam helmet that was fitted to patients by applying extra foam padding. ${ }^{41}$ In the current atmosphere of burgeoning health care costs, this may potentially be more cost-effective for the health care system as a whole.

\section{Are Cranial Orthoses Suitable for Children Older Than 1 Year of Age?}

Currently, most experts agree that starting cranial orthoses at 4 to 6 months of age is appropriate once more conservative measures have failed to correct the plagiocephaly. Kluba et al. in 2011 showed that patients who began helmet therapy prior to 6 months of age showed better relative and absolute reduction in head asymmetry when compared with patients who started after 6 months. ${ }^{13}$ They found that patients older than 6 months on average continued to have an abnormal cranial vault index at $4.5 \%$ at last follow-up. This suggests that a later starting age for helmet therapy may result in incomplete resolution of the asymmetry compared with beginning helmet therapy earlier. However, there have been published case reports in which infants older than 12 months of age were treated with dynamic orthotic cranioplasty with a reduction in cranial asymmetry. ${ }^{20}$

More recently, in 2013 Seruya et al. investigated the correction rate of plagiocephaly with helmet therapy in groups of infants stratified by age. ${ }^{36}$ They showed that the correction rate decreases with increasing infant age and that the correction rate reached the plateau rate of change (transcranial difference rate of $0.42 \mathrm{~mm} /$ week) once the infants were older than 32 weeks (approximately 8 months). As such, it appears that cranial orthotic therapy continues to be warranted for older infants, but the rate of correction is slower and cranial asymmetry may not be absolutely corrected. In addition, many researchers have mentioned the logistical difficulty parents have in keeping their now more-active infant in a helmet for long periods of time per day, which may contribute toward the relatively slower rate of change documented in the literature.

\section{What Are the Long-Term Outcomes of Deformational Plagiocephaly Treated With Helmet Therapy?}

Two studies investigating the long-term follow-up of infants treated with helmet therapy were reviewed..$^{15,39}$ It appears that in terms of the cranial asymmetry itself, infants treated with helmet therapy show relatively stable anthropometric measurements after discontinuation of helmet therapy. Lee et al. showed that 5 years after helmet therapy was discontinued, very little change happened in terms of cranial vault asymmetry values and orbitotragial depth asymmetry. ${ }^{15}$

Another study reviewed quality of life and parental satisfaction in long-term follow-up after treatment of plagiocephaly and found that there was no difference in quality of life between a healthy control group and infants treated with helmet therapy at 2 years after their initial clinic visit. ${ }^{9}$ Steinbok et al. ${ }^{39}$ investigated patient quality of life and parental satisfaction in school-aged children who were treated early in life with helmet therapy. Residual asymmetry was noted by parents in $58 \%$ of respondents, with $21 \%$ expressing some concern, and only $7 \%$ of parents stating they were very concerned about the asymmetry. The children were less aware of their head asymmetry, with only $8 \%$ of children noting any asymmetry. In terms of social impact, only $5 \%$ of children reported having been teased about their head asymmetry.

\section{Promising Future Studies}

Many review papers have acknowledged the lack of randomized control trials in the deformational plagiocephaly study. ${ }^{7,22,32}$ However, van Wijk et al. are trying to correct this void in the literature with their current pragmatic randomized controlled trial nested in a cohort study. ${ }^{43}$ Participants are recruited at 2-4 months of age when first diagnosed with deformational plagiocephaly. At 5 months of age, they will be reassessed; if the plagiocephaly persists, parents are offered the opportunity to participate in a randomized controlled trial for helmet therapy compared with conservative treatment. Parents who decline to participate will then be part of a nonrandomized controlled trial and allowed to choose helmet or nonhelmet therapy. Participants will be followed at set intervals until 24 months of age. Their outcome measures will include anthropometric measures and assessments of satisfaction in parents. Final results of this trial are expected in 2013.

\section{Conclusions}

In this study we demonstrate a lack of Class I literature evidence supporting the use of helmet therapy in deformational plagiocephaly and address the issues of appropriate use, cost, use in older children, and long-term 


\section{Orthotic (helmet) therapy in treatment of plagiocephaly}

outcomes. Hopefully, as new research studies address these issues, the clinical indications for helmet therapy in deformational plagiocephaly will be better defined.

\section{Disclosure}

The authors report no conflict of interest concerning the materials or methods used in this study or the findings specified in this paper.

Author contributions to the study and manuscript preparation include the following. Conception and design: Bauer, Goh. Acquisition of data: Goh. Analysis and interpretation of data: Goh. Drafting the article: Goh. Critically revising the article: Goh, Durham, Stotland. Reviewed submitted version of manuscript: Goh, Durham. Approved the final version of the manuscript on behalf of all authors: Bauer. Administrative/technical/material support: Bauer, Durham.

\section{References}

1. Argenta LC, David LR, Wilson JA, Bell WO: An increase in infant cranial deformity with supine sleeping position. J Craniofac Surg 7:5-11, 1996

2. Ayer A, Campbell A, Appelboom G, Hwang BY, McDowell M, Piazza M, et al: The sociopolitical history and physiological underpinnings of skull deformation. Neurosurg Focus 29(6):E1, 2010

3. Carter MR: Head moulding for plagiocephaly. Arch Dis Child 93:809-810, 2008

4. Clarren SK, Smith DW, Hanson JW: Helmet treatment for plagiocephaly and congenital muscular torticollis. J Pediatr 94:43-46, 1979

5. de Ribaupierre S, Vernet O, Rilliet B, Cavin B, Kalina D, Leyvraz P: Posterior positional plagiocephaly treated with cranial remodeling orthosis. Swiss Med Wkly 137:368-372, 2007

6. Elwood ET, Petronio J, Wood RJ: Parental satisfaction with the CranioCap: a new cranial orthosis for deformational plagiocephaly. Cleft Palate Craniofac J 42:340-343, 2005

7. Flannery AB, Looman WS, Kemper K: Evidence-based care of the child with deformational plagiocephaly, part II: management. J Pediatr Health Care 26:320-331, 2012

8. Gill D, Walsh J: Plagiocephaly, brachycephaly and cranial orthotic devices: misshapen heads and helmets. Arch Dis Child 93:805-807, 2008

9. Govaert B, Michels A, Colla C, van der Hulst R: Molding therapy of positional plagiocephaly: subjective outcome and quality of life. J Craniofac Surg 19:56-58, 2008

10. Graham JM Jr, Gomez M, Halberg A, Earl DL, Kreutzman JT, Cui J, et al: Management of deformational plagiocephaly: repositioning versus orthotic therapy. J Pediatr 146:258-262, 2005

11. Graham JM Jr, Kreutzman J, Earl D, Halberg A, Samayoa C, Guo X: Deformational brachycephaly in supine-sleeping infants. J Pediatr 146:253-257, 2005

12. Katzel EB, Koltz PF, Sbitany H, Emerson C, Girotto JA: Real versus perceived improvements of helmet molding therapy for the treatment of plagiocephaly. Plast Reconstr Surg 126:19e$21 \mathrm{e}, 2010$

13. Kluba S, Kraut W, Reinert S, Krimmel M: What is the optimal time to start helmet therapy in positional plagiocephaly? Plast Reconstr Surg 128:492-498, 2011

14. Kluba S, Schreiber R, Kraut W, Meisner C, Reinert S, Krimmel M: Does helmet therapy influence the ear shift in positional plagiocephaly? J Craniofac Surg 23:1301-1305, 2012

15. Lee RP, Teichgraeber JF, Baumgartner JE, Waller AL, English JD, Lasky RE, et al: Long-term treatment effectiveness of molding helmet therapy in the correction of posterior deformational plagiocephaly: a five-year follow-up. Cleft Palate Craniofac J 45:240-245, 2008
16. Lee WT, Richards K, Redhed J, Papay FA: A pneumatic orthotic cranial molding helmet for correcting positional plagiocephaly. J Craniofac Surg 17:139-144, 2006

17. Lipira AB, Gordon S, Darvann TA, Hermann NV, Van Pelt AE, Naidoo SD, et al: Helmet versus active repositioning for plagiocephaly: a three-dimensional analysis. Pediatrics 126: e936-e945, 2010

18. Littlefield T: Deformational plagiocephaly. J Neurosurg Pediatr 2:219-221, 2010 (Letter)

19. Littlefield TR: FDA regulation of cranial remodeling devices. J Prosthet Orthot 16 (4S):35-38, 2004

20. Littlefield TR, Pomatto JK, Kelly KM: Dynamic orthotic cranioplasty: treatment of the older infant. Report of four cases. Neurosurg Focus 9(3):E5, 2000

21. Littlefield TR, Saba NM, Kelly KM: On the current incidence of deformational plagiocephaly: an estimation based on prospective registration at a single center. Semin Pediatr Neurol 11:301-304, 2004

22. Looman WS, Flannery AB: Evidence-based care of the child with deformational plagiocephaly, Part I: assessment and diagnosis. J Pediatr Health Care 26:242-250, 2012

23. Losee JE, Mason AC, Dudas J, Hua LB, Mooney MP: Nonsynostotic occipital plagiocephaly: factors impacting onset, treatment, and outcomes. Plast Reconstr Surg 119:1866-1873, 2007

24. McGarry A, Dixon MT, Greig RJ, Hamilton DR, Sexton S, Smart H: Head shape measurement standards and cranial orthoses in the treatment of infants with deformational plagiocephaly. Dev Med Child Neurol 50:568-576, 2008

25. Meyer-Marcotty P, Böhm H, Linz C, Kunz F, Keil N, StellzigEisenhauer A, et al: Head orthesis therapy in infants with unilateral positional plagiocephaly: an interdisciplinary approach to broadening the range of orthodontic treatment. J Orofac Orthop 73:151-165, 2012

26. Mortenson P, Steinbok P, Smith D: Deformational plagiocephaly and orthotic treatment: indications and limitations. Childs Nerv Syst 28:1407-1412, 2012

27. Moss SD: Nonsurgical, nonorthotic treatment of occipital plagiocephaly: what is the natural history of the misshapen neonatal head? J Neurosurg 87:667-670, 1997

28. Mulliken JB, Vander Woude DL, Hansen M, LaBrie RA, Scott RM: Analysis of posterior plagiocephaly: deformational versus synostotic. Plast Reconstr Surg 103:371-380, 1999

29. Nield LS, Brunner MD, Kamat D: The infant with a misshapen head. Clin Pediatr (Phila) 46:292-298, 2007

30. Otway C: Plagiocephaly and awareness, prevention and treatment. Community Pract 81:38-40, 2008

31. Plank LH, Giavedoni B, Lombardo JR, Geil MD, Reisner A: Comparison of infant head shape changes in deformational plagiocephaly following treatment with a cranial remolding orthosis using a noninvasive laser shape digitizer. J Craniofac Surg 17:1084-1091, 2006

32. Robinson S, Proctor M: Diagnosis and management of deformational plagiocephaly. A review. J Neurosurg Pediatr 3: 284-295, 2009

33. Rogers GF, Miller J, Mulliken JB: Comparison of a modifiable cranial cup versus repositioning and cervical stretching for the early correction of deformational posterior plagiocephaly. Plast Reconstr Surg 121:941-947, 2008

34. Saeed NR, Wall SA, Dhariwal DK: Management of positional plagiocephaly. Arch Dis Child 93:82-84, 2008

35. Schaaf H, Malik CY, Streckbein P, Pons-Kuehnemann J, Howaldt HP, Wilbrand JF: Three-dimensional photographic analysis of outcome after helmet treatment of a nonsynostotic cranial deformity. J Craniofac Surg 21:1677-1682, 2010

36. Seruya M, Oh AK, Taylor JH, Sauerhammer TM, Rogers GF: Helmet treatment of deformational plagiocephaly: the relationship between age at initiation and rate of correction. Plast Reconstr Surg 131:55e-61e, 2013 


\section{J. L. Goh et al.}

37. Shamji MF, Fric-Shamji EC, Merchant P, Vassilyadi M: Cosmetic and cognitive outcomes of positional plagiocephaly treatment. Clin Invest Med 35:E266, 2012

38. Singh A, Wacogne I: What is the role of helmet therapy in positional plagiocephaly? Arch Dis Child 93:807-809, 2008

39. Steinbok P, Lam D, Singh S, Mortenson PA, Singhal A: Longterm outcome of infants with positional occipital plagiocephaly. Childs Nerv Syst 23:1275-1283, 2007

40. Stevens P, Downey C, Boyd V, Cole P, Stal S, Edmond J, et al: Deformational plagiocephaly associated with ocular torticollis: a clinical study and literature review. J Craniofac Surg 18:399-405, 2007

41. Thompson JT, David LR, Wood B, Argenta A, Simpson J, Argenta LC: Outcome analysis of helmet therapy for positional plagiocephaly using a three-dimensional surface scanning laser. J Craniofac Surg 20:362-365, 2009
42. van Vlimmeren LA, Helders PJ, van Adrichem LN, Engelbert RH: Torticollis and plagiocephaly in infancy: therapeutic strategies. Pediatr Rehabil 9:40-46, 2006

43. van Wijk RM, Boere-Boonekamp MM, Groothuis-Oudshoorn CG, van Vlimmeren LA, IJzerman MJ: HElmet therapy Assessment in infants with Deformed Skulls (HEADS): protocol for a randomised controlled trial. Trials 13:108, 2012

Manuscript submitted June 15, 2013.

Accepted July 24, 2013.

Please include this information when citing this paper: DOI: 10.3171/2013.7.FOCUS13260.

Address correspondence to: David F. Bauer, M.D., One Medical Center Dr., Lebanon, NH 03756. email: david.f.bauer@hitchcock. org. 